\title{
The influence of gas and humidity on the mineralogy of various salt compositions - implications for natural and technical caverns
}

\author{
Bettina Strauch $^{1}$, Martin Zimmer ${ }^{1}$, Axel Zirkler ${ }^{2}$, Stefan Höntzsch ${ }^{3}$, and Anja M. Schleicher ${ }^{1}$ \\ ${ }^{1}$ GFZ German Research Centre for Geosciences, Telegrafenberg, 14473 Potsdam, Germany \\ ${ }^{2} \mathrm{~K}+\mathrm{S}$ Aktiengesellschaft, Bertha-von-Suttner-Straße 7, 34131 Kassel, Germany \\ ${ }^{3} \mathrm{~K}+\mathrm{S}$ Windsor Salt Ltd., 30 Prospect Avenue, Windsor, ON, Canada
}

Correspondence: Bettina Strauch (betti@gfz-potsdam.de)

Received: 29 May 2018 - Revised: 6 August 2018 - Accepted: 11 August 2018 - Published: 29 August 2018

\begin{abstract}
Storage caverns are increasingly located in heterogeneous salt deposits and filled with various fluids. The knowledge of phase behaviour in heterogeneous systems of salt, liquid and gas and the requirements for reliable analytical techniques is, therefore, of growing interest. A method that allows for the continuous monitoring of mineral compositions at distinct humidity and gas content using XRD measurements is presented here. Various saliniferous mineral compositions have been investigated in pure $\mathrm{CO}_{2}, \mathrm{~N}_{2}$ or $\mathrm{CH}_{4}$ atmospheres with varying humidity in a closed chamber. All mineral compositions experience dissolution and/or mineral conversion reaction accompanied by volume loss. Dissolution-recrystallization reactions of complex mineral assemblages involving halite, sylvite, kieserite, carnallite and kainite were observed using this method. For carnallite-rich mineral assemblages, the mineral conversion from carnallite to sylvite was observed when humidity exceeded $50 \% \mathrm{RH}$. In the presence of $\mathrm{CO}_{2}$, acidification of the aqueous phase occurs which enhances the dissolution rate and reaction kinetics.
\end{abstract}

\section{Introduction}

Undisturbed salt formations are practically impermeable to fluids up to lithostatic pressure (e.g. Durup, 1994; Berest et al., 2001). The general integrity of salt formations is a result of the visco-plastic behaviour of salt rocks. Impressive examples for the isolation potential of salt rocks can be found in the Permian Zechstein deposits in the Werra-Fulda area (Germany) where pressurized gaseous, liquid and supercritical $\mathrm{CO}_{2}$ of Miocene volcanic origin were trapped with vol- umes of more than $100000 \mathrm{~m}^{3}$ (Herrmann, 1988; Minkley and Knauth, 2013).

Due to that specific characteristic together with the high solubility of saliniferous rocks, the construction of technical caverns in bedded or domal salt structures is nowadays common practice in order to create tight storage space for different commodities.

In compliance with the turnaround in energy policy, these facilities are of increasing importance for temporary gas storage as they are ideally suited to provide both a "source" and "sink" for gas supplies (Blanco and Faaij, 2018).

Preferably, storage caverns are of cylindrical shape in homogeneous rock salt deposits. However, a large number of cavern structures show strong variation in their contour which is primarily caused by variable salt mineralogy of the host rock. Salt formations may contain zones with lowsoluble impurities (e.g. anhydrite, dolomite) as well as intercalated layers with minerals of higher solubility (e.g. potash beds). Also, the formation of a "spongy" salt rock mass along the cavity walls where fluid infiltrates into the saliniferous host rock is described in the literature (Heekeren et al., 2009).

Due to the design of storage caverns, direct in situ observations, geochemical analyses and sampling along the cavern walls are impossible. Geotechnical studies often assume a sharp transition between fluid and rock along a defined cavity wall without considering geochemical salt solution effects of inhomogeneous salt rocks (e.g. Lux, 2009). However, the mineral composition of the cavern wall rock and the ionic composition and concentration of the fluid stored in the cavern are the main influencing parameters for the solution potential along the cavern walls and affect the location and evolution of potential migration fronts (e.g. Durie, 1964). 
In addition to man-made storage caverns in salt, natural geogenic cavernous structures are present in evaporitic rocks. These structures, often encountered during mining in subsurface salt deposits, represent a wide range of potential hazards that may affect mining activities or the surface environment (Höntzsch and Zeibig, 2014). The formation of geogenic caverns is related to rock-fluid interaction that can be triggered by metamorphic mineral dehydration reactions or initiated by tectonic events that either create new fluid pathways or even deliver fluids (Herrmann, 1983; Herbert and Schwandt, 2007). Generally, cavernous structures expand by dissolution processes at the contact between solid salt and fluid phase. The degree and rate of dissolution depends on both, the mineral compositions as well as on the fluid composition in terms of ionic saturation (Bach, 2010) and, to an unknown extend, the presence of a gaseous phase.

The geochemical characterisation of dissolutionrecrystallization processes in complex multiphase potassium-rich mineral assemblages is challenging (Kemp et al., 2016). Generally, depending on the minerals which are in contact with solution, various saturation stages are reached one after the other, causing a selective dissolution and fragmentation of minerals from their solid state, accompanied by recrystallization and various phase transitions (Voigt et al., 2001; Röhr, 1981; Durie, 1964). A most prominent salt reaction is the recrystallization of carnallite $\left(\mathrm{KMgCl}_{3} \cdot 6 \mathrm{H}_{2} \mathrm{O}\right)$ to sylvite $(\mathrm{KCl})$, associated with the release of an $\mathrm{MgCl}_{2}$-bearing brine and volume reduction (Braitsch, 1962).

The intrusion of undersaturated solutions along the periphery of cavern walls leads to a continuous change in effective porosity. This plays a decisive role for the integrity of cavernous structures in particular in contact with highly soluble and/or reactive mineral layers and potash seams. Detailed knowledge on the interaction between mineral dissolutionrecrystallization processes and porosity around cavern areas is, therefore, crucial in order to estimate the propagation potential of salt solution processes. This is likewise relevant for mining activities and for technical cavern usage where mineralogical heterogeneities occur.

Against this background, we investigate these processes using X-ray diffraction (XRD) analyses on a variety of saliniferous mineral compositions in a humidity chamber with defined gas composition.

\section{Sampling location}

All samples were collected in the Neuhof-Ellers potash mine located within the central German Werra-Fulda mining district. From a paleogeographic perspective, the Werra-Fulda Basin is situated in a southern embayment of the European Zechstein Basin. It contains cyclic evaporites of the Werra Formation (Z1). In the Neuhof area, the evaporites of the Zechstein are underlain by siliciclastic rocks of the Per-

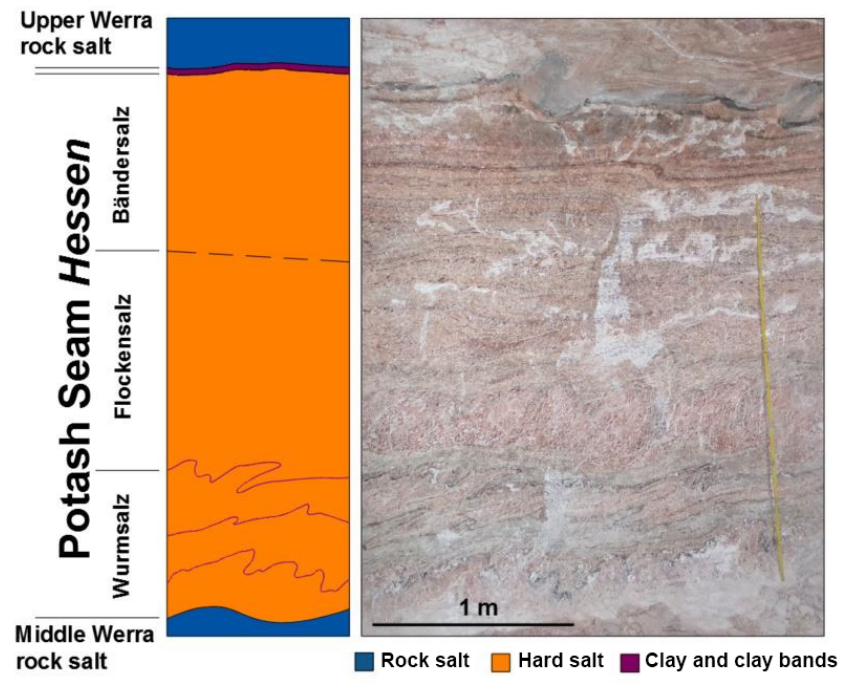

Figure 1. Typical appearance of sampling locations in Seam Hessen.

mian Rotliegend interval. The higher Zechstein-cycles (Z2Z7), on top of the Werra Formation consist of a siliciclastic succession with intercalated limestone and anhydrite layers (Beer and Barnasch, 2018). The Werra Formation is dominated by rock salt with a thickness up to $300 \mathrm{~m}$. Two potash seams (Seam Hessen and Seam Thüringen) separate the rock salt of the Werra Formation into three distinct units (Lower, Middle and Upper Werra rock salt). Seam Hessen mainly consists of hard salt (kieserite, sylvite, halite and anhydrite). It is overlain by several, potash mineral-bearing horizons which show a strong vertical and lateral heterogeneity and consist of kieserite, sylvite, carnallite, halite and anhydrite. Internally, three separate units are identified within potash Seam Hessen (Fig. 1). The "Wurmsalz", a hard salt with up to four strongly folded anhydritic clay bands represents the lower part of Seam Hessen. The middle part consists of massive, kieserite-rich hard salt with abundant sylvite lenses ("Flockensalz"). The "Bändersalz", a banded hard salt which is typically intercalated with brownish, halitic layers occurs in the upper part of Seam Hessen. Potash Seam Thüringen typically occurs around $50 \mathrm{~m}$ below Seam Hessen. Its lower part is dominated by a well-bedded hard salt with intercalated rock salt. Its upper part consists of a variety of rock types including carnallite, sylvite and hard salt.

Four samples $(20 \mathrm{~cm} \times 20 \mathrm{~cm})$ from the various units along the horizon of Seam Hessen were used for analyses. An additional sample of the underlying rock salt unit (Middle Werra rock salt), and a carnallite-dominated sample of Seam Thüringen were also analysed. The latter sample originates from a small, carnallite-rich lens in the upper part of the seam and is not representative of Seam Thüringen. 
(a)

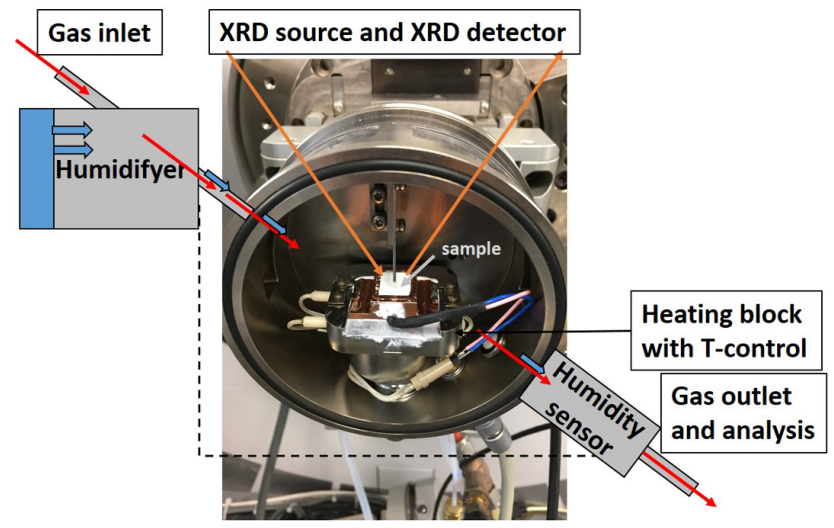

(b)

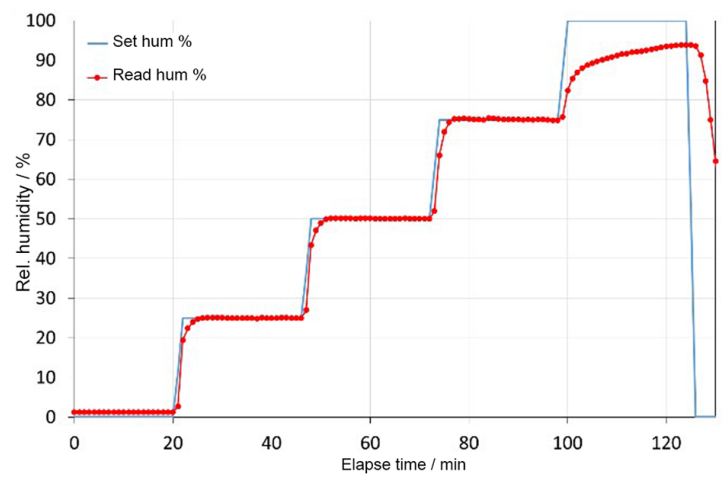

Figure 2. Schematic of the humidity chamber mounted to the XRD instrument (a). Log file data to illustrate the successive humidity increase with time (b). XRD measurements were performed during the relative humidity plateaus.

\section{Methods}

To avoid sample alteration by atmospheric air, the sample material was stored in air-tight bags that were evacuated immediately after filling. Due to the sample preparation requirements, the material experienced atmospheric indoor air conditions prior to the measurements for about $1 \mathrm{~h}$. The material was pre-crushed in an agate pestle and mortar, powdered using a Planetary Micro Mill (Pulverisette 7, Fritsch) and loaded into the sample holder.

The bulk mineralogy was determined using a PANalytical Empyrean powder diffractometer with $\mathrm{Cu}-\mathrm{K} \alpha$ radiation, automatic divergent and antiscatter slits and a PIXcel ${ }^{3 \mathrm{D}}$ detector. The diffraction data were recorded from 10 to $80^{\circ} 2 \theta$ via a continuous scan with a step-size of $0.0131^{\circ} 2 \theta$ and a scan time of $60 \mathrm{~s}$ per step. The generator settings were $40 \mathrm{kV}$ and $40 \mathrm{~mA}$. For quantitative analysis of the mineral components, the Rietveld algorithm BGMN was used (Bergmann et al., 1998).

To evaluate the effects of humidity and gas composition on mineral alteration, we employed a gas-flushed humidity chamber ("CHC plus" Cryo \& Humidity chamber, Anton Paar GmbH) mounted to the XRD instrument (Fig. 2a). The reaction chamber was equipped with a "TCU 110 " temperature control unit, designed to control the temperature directly at the sample holder. A controlled gas flow rate and regulated humidity was achieved by a temperature/humidity sensor placed within the chamber.

The temperature in the chamber was maintained constant at $298 \mathrm{~K}$ throughout the experiment. When the sample holder was mounted to the heating block, the chamber was closed and flushed with dry gas until the relative humidity kept at constant values of about $2( \pm 0.5) \% \mathrm{RH}$. The first XRD measurement was performed at this condition. Following that, diffraction data were recorded during the stepwise increase of the relative humidity from $25 \% \mathrm{RH}, 50 \% \mathrm{RH}, 75 \% \mathrm{RH}$ to $95 \%$ RH (see Fig. 2b). The gas exit of the humidity chamber was coupled to a mass spectrometer to permanently detect the gas composition of the pumped-through gas. Similar experiments were performed on all the samples.

In order to evaluate if the gas phase influences the mineral characteristics at various wetting conditions, three types of carrier gas were used; pure $\mathrm{N}_{2}, \mathrm{CO}_{2}$, and $\mathrm{CH}_{4}$. After the experiments, the sample weight was determined for information on weight loss or gain under humid conditions. A Vernier calliper was used to measure volume reduction in three spatial directions.

\section{Results}

\subsection{Mineral composition}

The mineral compositions of the four samples taken from Seam Hessen are shown in Fig. 3. Sample K1H-BS/o originates from below the upper clay bands at the very upper end of the "Bändersalz" of Seam Hessen. K1H-BS/u was sampled at the lower part of the "Bändersalz". The sample K1H-FS and K1H-WS originate from the "Flockensalz" and "Wurmsalz", respectively (Fig. 1). The major mineral species identified include halite $(\mathrm{NaCl})$, kieserite $\left(\mathrm{MgSO}_{4} \cdot \mathrm{H}_{2} \mathrm{O}\right)$, sylvite $(\mathrm{KCl})$, carnallite $\left(\mathrm{KMgCl}_{3} \cdot 6 \mathrm{H}_{2} \mathrm{O}\right)$, kainite $\left(\mathrm{KClMgSO}_{4} \cdot 3 \mathrm{H}_{2} \mathrm{O}\right)$ and anhydrite $\left(\mathrm{CaSO}_{4}\right)$.

Although all samples are part of Seam Hessen, their individual composition vary widely. Note, test specimens shown here are no representative means for Seam Hessen.

The upper-most sample K1H-BS/o comprises large quantities of halite and only minor portions of kieserite, sylvite and kainite. Samples K1H-BS/u, K1H-FS and K1H-WS illustrate the range of mineral assemblages present in the potash Seam Hessen with major components being sylvite, kieserite, halite and kainite. The subordinate minerals comprise carnallite and anhydrite. 


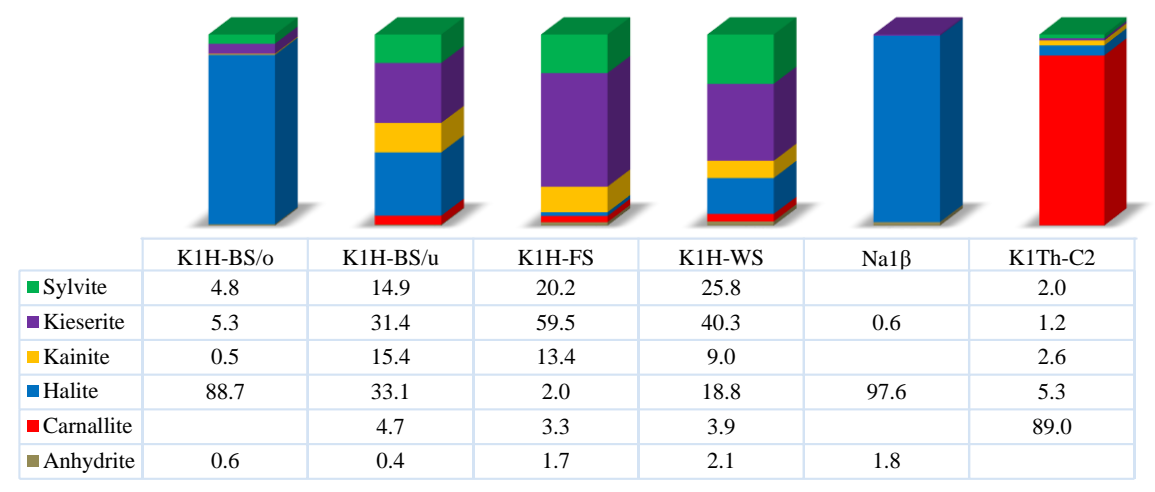

Figure 3. Mineralogical composition of test specimens (mineral concentrations in \%).

Sample Na1 $\beta$ is a halite dominated sample from the Middle Werra rock salt interval between Seam Hessen and Seam Thüringen.

Sample K1Th-C2 of Seam Thüringen is carnallite-rich with minor amounts of sylvite, kainite and halite. Kieserite is present with about $1 \%$, whereas anhydrite is below detection limit. Due to their similar atomic structure and common chemical composition, some peaks overlap in the XRD spectrum, making their identification difficult (Kemp et al., 2016). Errors for the quoted mineral concentrations are better than $\pm 2 \%$ for mineral concentrations $>50 \%, \pm 5 \%$ for mineral concentrations between $50 \%$ and $10 \%$. For mineral concentrations below $10 \%$ errors can be up to $\pm 10 \%$.

\subsection{Weight increase and volume loss}

In the course of the experiments, the sample weight increased by up to $10 \%$. This is primarily caused by sample wetting and not attributed to any mineral reaction. No distinctive correlation between the sample weight increase and the sample mineralogy or gas atmosphere was detected.

The humid atmosphere generally caused a volume decrease of the sample material in the range of $2 \%$ to $39 \%$. Differences do not correlate with the gas atmosphere but with mineral compositions. The sample with high carnallite content (K1Th-C2) experienced the largest volume loss of $39 \%$. The halite-rich samples K1H-BS/o and $\mathrm{Na} 1 \beta$ underwent volume losses of up to $15 \%$, samples K1H-BS/u, K1H-FS and K1H-WS with high kieserite content were largely unaffected by humidity in terms of volume loss. They reduced in size by approximately $2 \%$.

The volume decrease is assumed to be primarily due to the superficial salt dissolution in an ion deficient aqueous atmosphere. The differences in observed loss of volume are similar to dissolution rates for saliniferous minerals in fresh water as described in Röhr (1981). The dissolution rate of carnallite is more than double that of halite, whereas kieserite reveals a dissolution rate half that of halite. This is in agreement with the observed large volume loss of the carnallite-rich sample
K1Th-C2. However, it is likely that volume reduction is at least partly accounted by mineral conversion by dissolutionprecipitation reactions as previously described in the literature (e.g. Pippig, 1992).

\subsection{XRD measurements in the humidity chamber}

During each experiment, five XRD scans were performed to determine the changes of the sample specimens. The results are summarised in Fig. 4. The halite-dominated samples K1H-BS/o and Na1 $\beta$ reveal a small reduction of their halite content in favour of kieserite. In K1H-BS/u, K1H-FS and K1-WS, a decrease of kainite, sylvite and halite concentration is associated with an increase of the kieserite concentration. This is in agreement with the high relative solution rates of halite, sylvite and kainite compared to kieserite when exposed to fresh water (Röhr, 1981) and presumably not caused by mineral reactions. Changes in mineral concentrations appear to start at humidity levels over $50 \% \mathrm{RH}$. A very pronounced increase of the relative kieserite concentration occurs in sample K1H-BS/u at $>75 \% \mathrm{RH}$. This effect mirrors the dissolution of halite, resulting in a kieserite-rich rock composition. Smaller increases in the kieserite concentration was detected in samples K1H-FS and K1-WS, due to the initially lower halite concentration.

The XRD scans of the experiments with carnallitedominated samples K1Th- C2 (Fig. 5) reveal a mineral conversion, which is comparable to processes of salt metamorphism (Herrmann, 1983). The conversion starts at about $50 \% \mathrm{RH}$ and the carnallite concentration decreases from initially $>85 \%$ to finally $<10 \%$. In parallel, the sylvite concentration increases from $<2 \%$ to $75 \%$.

$\mathrm{N}_{2}$ and $\mathrm{CH}_{4}$-rich atmospheres do not affect the mineral conversion in terms of rate or degree. $\mathrm{A} \mathrm{CO}_{2}$-rich atmosphere, however, affects mineral dissolution and conversion rate noticeably. The influence is most significant in sample K1Th-C2. When exposed to $\mathrm{CO}_{2}$ atmosphere, the decrease in carnallite concentration starts earlier at $25 \% \mathrm{RH}$. 

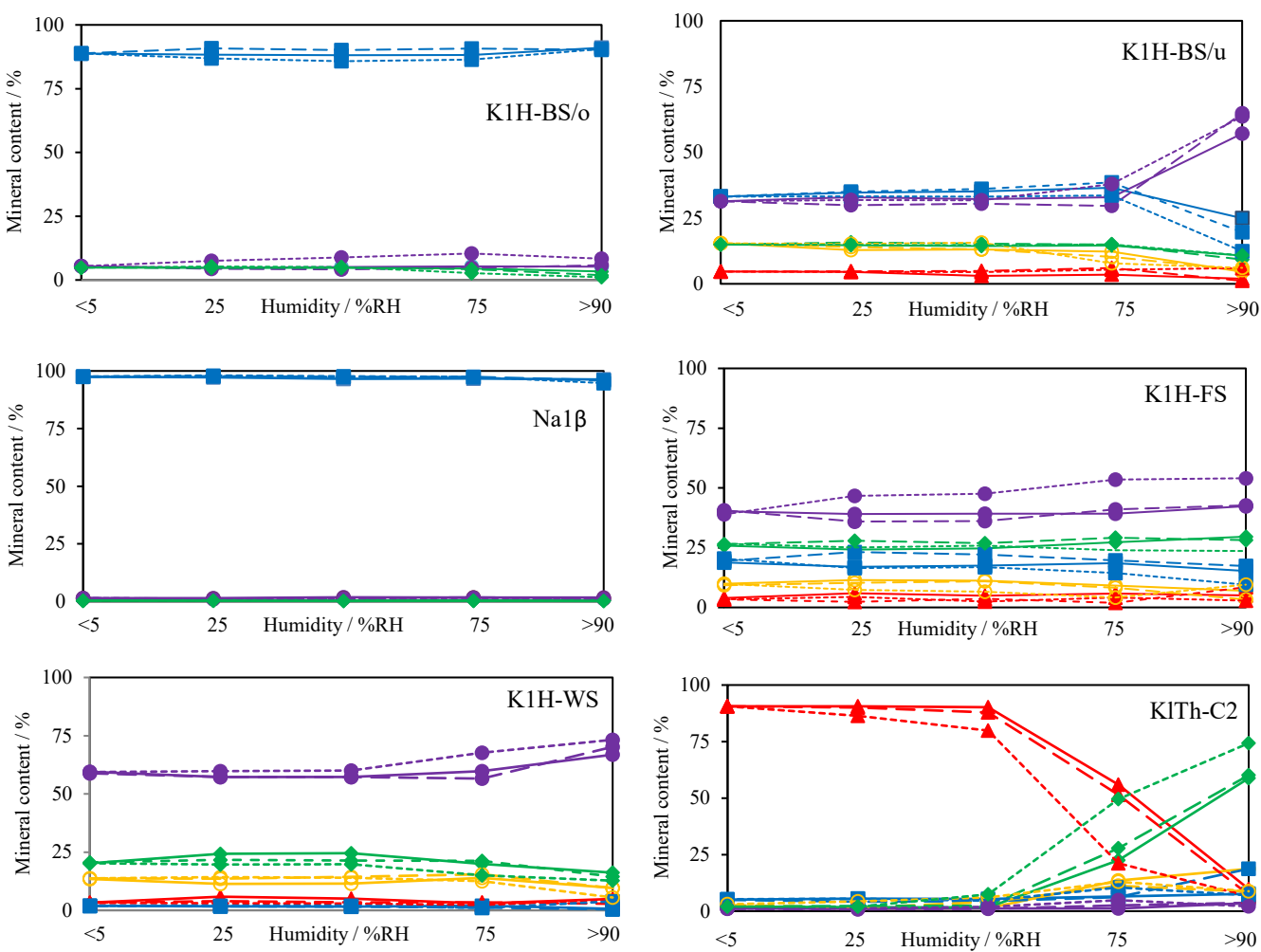

Figure 4. Changes of mineral content (blue squares - halite, red triangles - carnallite, yellow circles - kainite, violet dots - kieserite, green diamonds - sylvite) with increasing humidity. X-ray measurements were performed at $<5 \% \mathrm{RH}, 25 \% \mathrm{RH}, 50 \% \mathrm{RH}, 75 \% \mathrm{RH}$ and $>90 \% \mathrm{RH}$. The same experiment was performed with different gases: solid line, dashed line and dotted line indicate $\mathrm{N}_{2}, \mathrm{CH}_{4}$ and $\mathrm{CO}_{2}$ atmosphere, respectively.

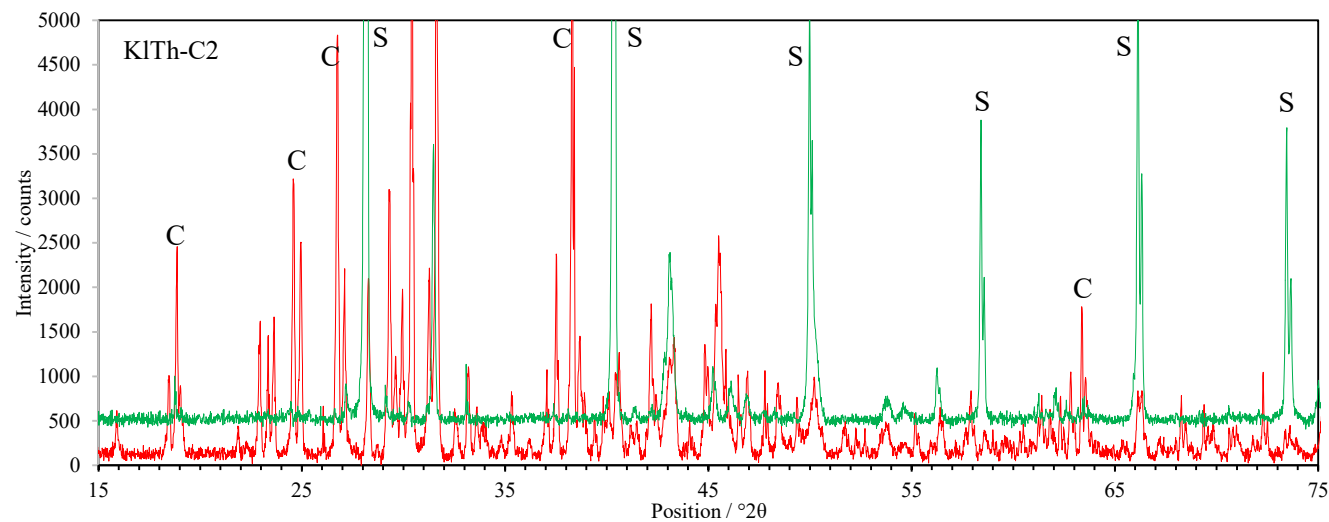

Figure 5. XRD patterns of the carnallite-rich sample K1Th-C2. Shown in red is the pattern of the starting composition at low humidity, shown in green is the final mineral composition at high humidity during the final phase of the experiment. Marked with $\mathrm{S}$ and $\mathrm{C}$ are some diagnostic peaks for sylvite and carnallite, respectively.

The effect of enhanced mineral dissolution is also visible, to a lesser degree, in all other samples of Seam Hessen.

Ostwald coefficients suggests that $\mathrm{CO}_{2}(0.9368)$ dissolves much better in water compared to $\mathrm{CH}_{4}(0.03668)$ and $\mathrm{N}_{2}$ (0.01686) (Messer Griesheim, 1989). In contrast to $\mathrm{CH}_{4}$ and
$\mathrm{N}_{2}, \mathrm{CO}_{2}$ forms a weak acid, when dissolved in water, increasing mineral solubility. 


\section{Discussion}

The experiments comprise mineral assemblages involving $\mathrm{NaCl}-\mathrm{KCl}-\mathrm{MgCl}_{2}-\mathrm{MgSO}_{4}-\mathrm{CaSO}_{4}-\mathrm{H}_{2} \mathrm{O}$. If dry saliniferous rocks experience humidity, wetting occurs. This effect causes selective mineral dissolution in order of the relative salt dissolution rate. The initial dissolution rate is assumed to correlate to fresh water dissolution where carnallite dissolves more than twice as fast and kieserite only half as fast as halite. The ion load in the wet phase increases and its composition will change permanently due to competing effects of fresh water delivery by humid atmosphere and salt solution. The latter results in the formation of an ion-rich aqueous phase that, depending on its composition, increases the dissolution rate for some mineral phases. Due to the dynamics of the process and the diversity of phases, the ion concentrations of the coexisting brine cannot be quantified. Parallel to dissolution processes, secondary crystallisation may occur. These processes are running simultaneous in an open, dynamic system and do not allow for confident qualitative and mass balancing studies on distinct solution-precipitation reactions.

Simple effects, however, can be rapidly detected. For carnallite-rich mineral compositions, a nearly complete mineral conversion from carnallite to sylvite was observed. Other saliniferous rocks show only small changes in the overall mineral composition which can largely be attributed to dissolution effects.

An enhancing effect of $\mathrm{CO}_{2}$ to the reaction kinetics and dissolution rate is clearly visible. This is caused by the high solubility of $\mathrm{CO}_{2}$ in water accompanied by the acidification of the wetting fluid.

\section{Conclusions}

The demand for new storage facilities in salt remains high, while the best suited sites with most-homogeneous deposits become increasingly rare. Therefore, heterogeneous salt deposits are considered to serve as host rock for storage caverns. This requires a detailed knowledge of phase behaviour in the heterogeneous systems of salt, liquid and gas.

In this context, the impact of humidity and gas on various saliniferous mineral compositions was studied by applying non-ambient XRD measurements for continuous in situ monitoring of salt mineralogy during wetting in a defined gas atmosphere. These simulations of geochemical interactions between water, gas and salt at laboratory scale allow for the evaluation of the influence of a variety of cavern fillings and host rock compositions on mineral alteration in the cavityrock transition zone and add to geotechnical assessments of cavern characteristics.

The preliminary results presented here, show that $\mathrm{CO}_{2}$ and/or a high content of carnallite accompanied to mineral reactions and volume loss should be critically considered when approaching questions of cavern formation and integrity in heterogeneous salt deposits.

Data availability. The data will be accessible after publication in the data repository of the GFZ at: http://gfzpublic.gfz-potsdam.de/ pubman/ (last access: 28 August 2018).

Competing interests. The authors declare that they have no conflict of interest.

Special issue statement. This article is part of the special issue "European Geosciences Union General Assembly 2018, EGU Division Energy, Resources \& Environment (ERE)". It is a result of the EGU General Assembly 2018, Vienna, Austria, 8-13 April 2018.

Acknowledgements. We thank the staff of the Neuhof-Ellers potash mine for their help and great support with all logistical questions and sampling. We also highly appreciate the proofreading of the manuscript by Mary Lavin-Zimmer. This study is part of the project ProSalz and we gratefully acknowledge the financial support of the BMBF within the framework program Geo:N - geoscience for sustainability. The manuscript highly benefitted from the reviews of Simon J. Kemp and Renata van der Weijden.

The article processing charges for this open-access

publication were covered by a Research

Centre of the Helmholtz Association.

Edited by: Michael Kühn

Reviewed by: Simon J. Kemp and Renata van der Weijden

\section{References}

Bach, J.: Untersuchung der lösekinetischen Vorgänge beim Ersaufen der Staßfurter Kaligruben, Abschlussbericht FVV TV4, Tagungsband, 1-18, 2010.

Beer, W. and Barnasch, L.: Werra-Fulda-Becken, SDGGMonography, in press, 2018.

Berest, P., Bergues, J., Brouard, B., Durup, J. G., and Guerber, B.: A salt cavern abandonment test, Int. J. Rock Mech. Min., 38, 357368, 2001.

Bergmann, J., Friedel, P., and Kleeberg, R.: BGMN - A new fundamental parameter based Rietveld program for laboratory X-ray sources, its use in quantitative analysis and structure investigations, Commission of Powder Diffraction, International Union of Crystallography, CPD Newsl., 20, 5-8, 1998.

Blanco, H. and Faaij, A.: A review at the role of storage in energy systems with a focus on Power to gas and long-term storage, Renew. Sust. Energ. Rev., 81, 1049-1086, 2018.

Braitsch, O.: Entstehung und Stoffbestand der Salzlagerstätten, in: Mineralogie und Petrographie in Einzeldarstellungen, edited by: Engelhardt, W. V. and Zemann, J., Bd. 3, Springer Verlag, Berlin, Germany, 232 pp., 1962. 
Durie, R. W.: Mechanism of the Dissolution of Salt in the Formation of Underground Salt Cavities, Soc. Petrol. Eng. J., IV, 183-190, 1964.

Durup, J. G.: Long-Term Tests for Tightness Evaluations with Brine and Gas in Salt (Field-Test No. 2 with Gas), SMRI Research and Development Project Report, Proc. S.M.R.I. Fall Meeting, September 1994, Hannover, Germany, 1994.

Heekeren, H. V., Bakker, T., Duquesnoy, T., Ruiter, V. d., and Mulder, L.: Abandonment of an extremely deep Cavern at Frisia Salt, Solution Mining Research Institute Technical Conference, 2728 April 2009, Krakow, Poland, 1-13, 2009.

Herbert, H. J. and Schwandt, A.: Salzlösungszuflüsse im Salzbergbau Mitteldeutschlands, GRS, Köln, Germany, p. 198, 2007.

Herrmann, A. G.: Radioaktive Abfälle - Probleme und Verantwortung, Springer-Verlag, Berlin, Heidelberg, Germany, 258 pp., 1983.

Herrmann, A. G.: Gase in marinen Evaporiten, PTB 2/88, 1-33, 1988.

Höntzsch, S. and Zeibig, S.: Geogenic caverns in rock salt formations - a key to genetic processes and hazard potential, Schriftenreihe der Deutsche Gesellschaft für Geowissenschaften, Heft 85, GeoFrankfurt, 21-24 September 2014, Johann Wolfgang Goethe Universität Frankfurt a.M., Germany, 2014.

Kemp, S. J., Smith, F. W., Wagner, D., Mounteney, I., Bell, C. P., Milne, C. J., Gowing, C. J. B., and Pottas, T. L.: An improved approach to characterize potash-bearing evaporite deposits, evidenced in North Yorkshire, UK, Econ. Geol., 111, 719-742, 2016.
Lux, K.-H.: Design of salt caverns for the storage of natural gas, crude oil and compressed air: Geomechanical aspects of construction, operation and abandonment, in: Underground Gas Storage: Worldwide Experience and Future Development in the UK and Europe, edited by: Evans, D. J. and Chadwick, R. A., Geol. Soc. Spec. Publ., 313, 93-128, 2009.

Messer Griesheim: Gase-Handbuch, Messer Griesheim GmbH, Frankfurt a. M., Germany, 341 pp., 1989.

Minkley, W. and Knauth, M.: Integrity of rock salt formation under static and dynamic impact, Natural Analogues for Safety Cases of Repositories in Rock Salt, Salt Club Workshop Proceedings, 5-7 September 2013, Braunschweig, Germany, 5-7, 177-195, 2013.

Pippig, M.: Über das Vorkommen einer Kristallsalzschlotte im Kalibergwerk Merkers, Kali und Steinsalz, 11, 2-7, 1992.

Röhr, H. U.: Lösungsgeschwindigkeiten von Salzmineralen beim Ausspülen von Hohlräumen im Salz, Kali und Steinsalz, 8, 103 $111,1981$.

Voigt, W., Voigt, H., and Jockel, A.: Lösungsprozesse im carnallitischen Salzgebirge - geochemische Modellierung und praktische Bedeutung, Exkursionsführer und Veröffentlichungen der GGW, Berlin, Germany, 6.23, 2001. 